http://dx.doi.org/10.1590/0370-44672019730055

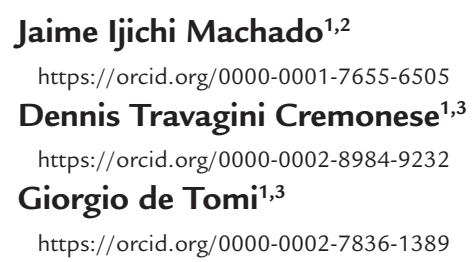

${ }^{1}$ Universidade de São Paulo - USP, Departamento de Engenharia de Minas e de Petróleo, São Paulo - São Paulo - Brasil.

E-mails: ${ }^{2}$ jaime.machado@alumni.usp.br, ${ }^{3}$ dennis.travagini@dynamine.com.br, 4ydetomi@usp.br

\title{
Mining
}

\section{Development of a low-cost alternative for the monitoring of the ore hauling production indicators in small-scale mining}

\begin{abstract}
Small and medium-sized mining represent an important part of a country's mineral economy. These companies, although substantial and numerous, have low investment potential in their development through new technologies. One of the problems small and medium mining companies face is the ore hauling production monitoring. This operation alone can constitute as much as $60 \%$ of the mining operating cost, due to intense fuel and tires consumption, and represents more than a half of the greenhouse gas emission in a quarry. Aiming at this problem, this article purposes to answer the following question: Is it possible to monitor the production of the ore hauling in small mining with a low-cost system? The results showed that yes, it is possible, using off-the-shelf solutions, regular office software and low use of labor. The results were validated in a quarry located in the State of São Paulo, where a US\$ 490 system presented consistent results, improvements in fuel consumption and benefits to the environment.
\end{abstract}

Keywords: small-scale mining, ore hauling, low-cost, monitoring.

\section{Introduction}

This research was conceived from the experience of the author when working in a small-scale mining company. The business, a quarry, is a typical small-scale family-run business, being responsible for the employment and livelihood of around 40 families and providing minerals for construction to the local market. Like many companies of the same size, the quarry presents cost management problems, especially the cost of the ore hauling due to the difficulty in the implementation of computerized tools.

The following paragraphs present the result of the research conducted on the importance of small businesses in the economy of a country, and their difficulty in implementing new technologies. Then the importance of the ore transportation in the overall cost of mining and its impact on the environment are stated. Thus, the article leads to an attempt to provide a solution to the problem raised: a low-cost alternative for monitoring of the ore hauling production indicators in small-scale mining.

Small and medium-sized enterprises (SMEs) are responsible for most of a country's economy and jobs generation (Hillary, 2017). Enterprises classified as SME are estimated to account for at least $95 \%$ of registered firms worldwide. In Europe, for example, this number is well over 99\% (World Bank Group, 2009). According to Ayyagari, Beck and Demirguc-Kunt (2003), a research from a 55-country sample showed that SMEs (formal and informal) generate about $65-70 \%$ of the gross domestic product (GDP) across all country income levels. Brazilian SMEs participate with about $20 \%$ of GDP and contribute with approximately $40 \%$ of the work income (SEBRAE, 2012). Similarly, small-scale mining companies are as important as large-scale mining, mainly in terms of the number of people employed
(Hentshel; Hruschka; Priester, 2002). In Brazil, small and medium-sized mining corresponds to $95 \%$ of the mines (DNPM, 2010).

The United Nations defines small mining as "any mining operation with annual production of raw material of 50,000 t or less" (Bugnosen, 2006). In Brazil, the National Mining Agency (ANM) classifies mining companies according to their annual gross Run of Mine (ROM) production. According to this classification, it is possible to define a small mining operation as the one with a gross annual production of up to $100,000 \mathrm{t}$ and medium mining as the one with a gross annual production of up to $1,000,000 \mathrm{t}$ (DNPM, 2010). This definition will be adopted in this study.

Although companies of this size are numerous, it is not easy for them to access new technologies. According to Silva (1998), small and medium-sized enterprises face difficulties investing in their 
development, since their investment potential is low compared to large companies.

Other authors (Dewan; Riggins, 2005; Bach; Zoroja; Vukšić, 2013) argue that small and medium-sized enterprises have the least access to Information and Communication Technologies - ICT. In the contemporary business world, the companies rely on technology to support strategic thinking (Carr, 2003). Investments in this kind of technology are a competitive necessity if firms are willing to compete in the globalized world (Barclay; Duggan, 2008; World Economic Forum, 2010). Knowing that the use of technology brings many benefits to the company, a question should be answered: Is mining a high-tech industry?

There are examples of the stateof-the-art technology being used in large mining companies. Rio Tinto has implemented innovative systems in its mines to increase the efficiency of processes, such as autonomous ore transport equipment and new sorting systems, capable of separating the gangue even before the material reaches the beneficiation plant (Rio Tinto, 2014). Newmont Mining Corporation has presented very satisfactory results integrating the geology and geostatistics systems with the operation (Schutz et al., 2006). Vale started the test with autonomous trucks in the Brucutu mine (municipality of São Gonçalo do Rio Abaixo in Brazil) in January 2018 with positive results (Vale, 2018).

Bartos (2007) tried to answer that question in his study. The author concluded that this sector is a great user of sophisticated technologies, as

\section{Material and method}

To answer the question posed in the previous item, the idea is to keep the solution simple, using off-the-shelf equipment whenever possible, together with regular software normally used in offices and minimizing the need for the use of labor. For validation, the proposed method was tested in a quarry located in São Paulo State in the form of an application example.

The quarry is a typical medium sized family managed company in Brazil that employs around 40 workers, and has a 600,000 t annual ROM production, with no production control system. The only firm information that is recorded presented in the previous paragraph. And that, excluding industries focused on the development of high technology, mining has the same level of innovation as other industries. However, he also concludes that the use of sophisticated technologies is more restricted to large mining companies.

Knowing that mining is not a less technological sector than other industrial sectors, one must then investigate why the adoption of new technologies is so complicated in SMEs. Taylor (2015) selected the key factors influencing the ICT adoption by SME, dividing them into internal and external factors. The internal factors are entrepreneur characteristics, organizational culture, structure and resources, relational complexities (e.g. family involvement in the SMEs operation), ICT awareness, knowledge and know-how of staff. The external factors are business networks, trading partners, industrial type, service providers, ICT consultants and vendors, government support and policies, economic and competitive pressures, and types of ICT products in the marketplace.

Giotopoulos et al (2017) conducted a similar study using a large database of Greek SMEs. The data revealed that it is hard to convince the owners of SMEs of the advantages of long-term adoption of new technologies, since the adoption requires investment in training and deployments. Another important point is the level of education of workers, the higher the skills, the easier it is to assimilate new technologies.

Therefore, a large gap emerges: the thousands of small and medium-sized mining companies have similar or even greater problems than large companies,

is the mass of rock that is sold. This is because all mining operations in Brazil are obliged to issue the invoices through the measurement via truck scale, which must be calibrated periodically. All other production information is estimated from manual annotations.

The process begins with the rock drilling using a hydraulic drill. The holes are loaded with explosives for rock fragmentation. The fragmented rocks are then loaded onto the trucks by hydraulic excavators. The hauling trucks travel an average distance of 1,000 meters to the dumping location, and the difference between loading and but do not have the financial and human resources to implement solutions.

One of the problems small and medium mining companies face is the ore hauling production monitoring, since this operation alone can make up as much as $60 \%$ of the mining operating cost (May, M. A., 2012). Haulage operating costs are considerable due to intense fuel and tire consumption (Rodovalho; Lima; De Tomi, 2016). In addition, this operation contributes to more than half of the emission of greenhouse gases in a quarry (Kittipongvises; Chavalparit; Sutthirat, 2016).

Rodovalho, Lima and De Tomi (2016) studied the variables related to fuel consumption of mining trucks, using statistical analysis and mathematical modeling tools, and reached a $10 \%$ reduction of diesel consumption. According to the article, the study was carried out in a large iron mining operation in Brazil.

Haulage performance indicators monitoring is nothing new for large mines, but in a small or medium mine with no or low operational monitoring, starting to track the most representative cost driver - hauling operation - should bring a huge impact both economically and environmentally. Monitoring such a supply demanding operation is the key to the reduction of greenhouse gas emissions (Levesque; Millar; Paraszczac, 2014).

However, as stated before, it is difficult for a small or medium mining operation to invest in this kind of technology. This study aims to answer the question: Is it possible to monitor the production of the ore hauling in a small mining operation with a low-cost system?

unloading altitudes is approximately $80 \mathrm{~m}$.

The ROM processing to produce civil construction material is basically composed of 3 stages of crushing and screening to separate the crushed stone by granulometric fraction. The quarry produces gravel according to the granulometric distributions required by the construction industry for each type of use, as presented in Table 1. This final product is loaded onto the client's trucks through wheel loader, and the weight of each truck is measured at the entrance and exit for issuing the invoice. 
Table 1 - Quarry products and their respective uses.

\begin{tabular}{c|c|c}
\hline Commercial name & Size distribution & Common use \\
\hline Very fine gravel & $0-4.8 \mathrm{~mm}$ & Asphalt plants, precast parts, mortar \\
\hline Fine gravel & $4.8-9.5 \mathrm{~mm}$ & Beams, pre-cast slabs, interlocking floors, pipes, bricks, slabs and finishes \\
\hline Medium gravel & $9.5-19 \mathrm{~mm}$ & Most used gravel in construction. Manufacture of concrete, beams, slabs \\
\hline Coarse gravel & $19-25 \mathrm{~mm}$ & Manufacture of concrete with more strength. Foundations and floors of greater thickness; \\
\hline Very coarse gravel & $25-50 \mathrm{~mm}$ & Track ballast for railroad ties \\
\hline Cobble & $50-300 \mathrm{~mm}$ & Drainage works, rockfill \\
\hline Crusher run & $0-50 \mathrm{~mm}$ & Asphalt base \\
\hline
\end{tabular}

Auxiliary services such as road conservation are carried out by wheel loaders and water truck. The supply of mobile equipment is carried out by a maintenance truck. Table 2 shows a list of the main equipment of the quarry.

Table 2 - Main equipment list.

\begin{tabular}{c|c|c|c}
\hline Description & Quantity & Power per unit (kw) & Supply \\
\hline Hydraulic rock drill & 1 & 170 & Diesel \\
\hline Hydraulic excavator & 3 & 240 & Diesel \\
\hline Haul truck & 4 & 260 & Diesel \\
\hline Wheel loader & 2 & 220 & Diesel \\
\hline Water truck & 1 & 150 & Diesel \\
\hline Maintenance truck & 1 & 150 & Diesel \\
\hline Jaw crusher & 1 & 150 & Electricity \\
\hline Cone crusher & 2 & 220 & Electricity \\
\hline Screen & 2 & 45 & Electricity
\end{tabular}

\subsection{Data collection}

Data collection is performed through a GPS sensor installed in the truck. This sensor should be able to capture the geographic coordinates during the movement of the truck. This data must be saved in a log file to be used on a computer where this data is processed.

Thus, the sensor should only collect the data. All processing will be performed on a computer equipped with a spreadsheet program. As there will

\subsection{Data processing}

As previously stated, the processing of data generated from the GPS sensor is applied to a spreadsheet program. In the application example, Microsoft Excel was used because it is one of the be no data processing on the sensor, a simple GPS sensor with little or no customization is used.

With the advancement and popularization of platforms for developers like Raspberry, it would be possible to integrate the sensor directly with the computer through a wireless connection and applications stored in a cloud server. So, it would be possible to broadcast live the positioning of the truck.

most popular in the world, being used by more than 1 billion users (Arghire, 2012). However, the processing can be performed in any program that accepts logical data manipulation.
To keep the solution simple and at the lowest possible cost, in the application example a Garmin Etrex 30X portable GPS was used, and data was transmitted manually to the computer via USB cable.

In order to record the average diesel consumption, the daily supply of the trucks was also monitored by checking the volume of fuel that was fueled in each truck.

In the application example, the chosen GPS sensor generated a track file during the truck data collection. The relevant information recorded in the track file is displayed in Table 3.

Table 3 - Track file.

\begin{tabular}{c|c|c|c|c|c|c|c}
\hline Point ID & $\begin{array}{c}\text { Elevation } \\
(\mathbf{m})\end{array}$ & $\begin{array}{c}\text { Leg distance } \\
(\mathbf{m})\end{array}$ & Leg time & $\begin{array}{c}\text { Leg speed } \\
(\mathbf{k m} / \mathbf{h})\end{array}$ & Time & $\begin{array}{c}\text { X position } \\
(\mathbf{m})\end{array}$ & $\begin{array}{c}\mathrm{Y}_{\text {position }} \\
(\mathbf{m})\end{array}$ \\
\hline $\mathrm{P}_{1}$ & $\mathrm{E}_{1}$ & $\mathrm{LD}_{1}$ & $\mathrm{LT}$ & $\mathrm{V}_{1}$ & $\mathrm{~T}_{1}$ & $\mathrm{X}_{1}$ & $\mathrm{Y}_{1}$ \\
\hline $\mathrm{P}_{2}$ & $\mathrm{E}_{2}$ & $\mathrm{LD}_{2}$ & $\mathrm{LT}_{2}$ & $\mathrm{~V}_{2}$ & $\mathrm{~T}_{2}$ & $\mathrm{X}_{2}$ & $\mathrm{Y}_{2}$ \\
\hline $\mathrm{P}_{3}$ & $\mathrm{E}_{3}$ & $\mathrm{LD}_{3}$ & $\mathrm{LT}_{3}$ & $\mathrm{~V}_{3}$ & $\mathrm{~T}_{3}$ & $\mathrm{X}_{3}$ & $\mathrm{Y}_{3}$ \\
\hline $\mathrm{P}_{\mathrm{n}}$ & $\mathrm{E}_{\mathrm{n}}$ & $\mathrm{LD}_{\mathrm{n}}$ & $\mathrm{LT}_{\mathrm{n}}$ & $\mathrm{V}_{\mathrm{n}}$ & $\mathrm{T}_{\mathrm{n}}$ & $\mathrm{X}_{4}$ & $\mathrm{Y}_{\mathrm{n}}$ \\
\hline
\end{tabular}


Description of the data collected:

- Point ID $\left[\mathrm{P}_{n}\right]$ : Increasing numbering that identifies the point;

- Elevation $\left[\mathrm{E}_{\mathrm{n}}\right]$ : Elevation ob- tained from the barometric sensor in meters;

- Leg distance $\left[\operatorname{LD}_{\mathrm{n}}\right]:$ Geometric distance between the points $P_{n}+1$ and

$$
L D_{n}=\sqrt{\left(Y_{n+1}-Y_{n}\right)^{2}+\left(X_{n+1}-X_{n}\right)^{2}}
$$

- Leg time $\left[L T_{n}\right]$ : Time between the moment that $\mathrm{P}_{n}+1$ and $\mathrm{P}_{\mathrm{n}}$ was collected (Equation 2);

$$
L T_{n}=T_{n+1}-T_{n}
$$

- Leg speed $\left[\mathrm{V}_{\mathrm{n}}\right]$ : speed of the truck during the leg, given by the Leg distance $\left[\mathrm{LD}_{n}\right]$ and the Leg time $\left[\mathrm{LT}_{\mathrm{n}}\right]($ Equation 3$)$ in $\mathrm{km} / \mathrm{h}$;

$$
V_{n}=\frac{L D_{n}}{L T_{n}}
$$

- Time $\left[T_{n}\right]$ : Time that the point $P_{n}$ was collected (including date information $-\mathrm{dd} / \mathrm{mm} /$ yyyy hh:mm:ss);

-X position $\left[\mathrm{X}_{\mathrm{n}}\right]$ : Geographic UTM longitude in meters;

- $Y$ position $\left[Y_{n}\right]$ : Geographic UTM

\section{System elements}

For the spreadsheet program to be able to classify the legs, it is first important to define some parameters:

- Loading point [LP]: geographic point in UTM where the truck should be loaded. This data is represented as $[L P]=\left(L P_{x}, L P_{y}\right)$, being $L P_{x}$ the longitude in meters, and LPy the latitude in meters;

- Crusher point [CP]: geographic point in UTM where the crusher is installed. This data is represented as $[C P]=\left(C P_{x}, C P_{y}\right)$, being $C P_{x}$ the longitude latitude in meters;

The spreadsheet program should then automatically define the sections of interest for data analysis: loading legs, loaded transport legs, unloading on the crusher legs, unloaded transport legs.

in meters, and $\mathrm{CP}_{y}$ the latitude in meters;

- Proximity radius [R]: Radius in meters which defines the area around the loading point [LP];

- Speed tolerance $\left[\mathrm{V}_{\text {tol }}\right]$ : Minimum velocity for a movement to be considered. This is necessary because of the sensor error. For instance, if the error of the sensor is $5 \mathrm{~m}$ and 2 points were collected within 1 second difference, the truck even stopped can present in the collected data a speed greater than zero due to the
$P_{n}$. Since the distance between points is always short, it can be calculated by the Equation 1 in meters;

\section{Loading legs [ $\left.\mathrm{LL}_{\mathrm{n}}\right]$}

With the data defined in the previous item, the following logic is used to define the loading leg $\left[\mathrm{LL}_{n}\right]$ :

$$
\text { IF }\left[D_{L P}\right]<[R] \text { AND }\left[M_{n}\right]=0 \text {, THEN }\left[L_{n}\right]=1 \text {, ELSE }\left[L_{n}\right]=0
$$

When $\left[L L_{n}\right]=1$, it is a loading leg. When $\left[L_{n}\right]=0$, it is not a loading leg;

\section{Unloading on the crusher legs $\left[\mathrm{CL}_{\mathrm{n}}\right]$}

To classify the leg as "unloading on the crusher leg" $\left[\mathrm{CL}_{n}\right]$ the spreadsheet program should follow the logic:

$$
\operatorname{IF}\left[D_{c p}\right]<[R] \text { AND }\left[M_{n}\right]=0, \operatorname{THEN}\left[C_{n}\right]=1, \operatorname{ELSE}\left[\mathrm{CL}_{n}\right]=0
$$

\section{Loaded/unloaded transport legs $\left[\mathrm{LTL}_{\mathrm{n}}\right]$}

To classify the leg as "loaded transport leg" the spreadsheet program should follow the logic:

$$
\begin{array}{r}
\mathbb{I F}\left[\mathrm{LL}_{n}\right]=0 \text { AND }\left[\mathrm{CL}_{n}\right]=0, \operatorname{THEN}\left[\mathrm{LTL}_{n}\right]=\left[\mathrm{LTL}_{n-1}\right], \\
\mathbb{I F}\left[\mathrm{LL}_{n}\right]=1, \operatorname{THEN}\left[\mathrm{LTL}_{n}\right]=1, \operatorname{ELSE}\left[\mathrm{LTL}_{n}\right]=0
\end{array}
$$

Where $\left[L T L_{n}\right]$ is a string which will save when the leg is a Loaded Transport Leg. When $\left[L T L_{n}\right]=1$, it is a Loaded Transport Leg, when $\left[\mathrm{LTL}_{\mathrm{n}}\right]=0$, it is an Unloaded Transport Leg. 


\section{Cycle count $\left[\mathrm{CC}_{n}\right]$}

To identify each truck cycle the spreadsheet program should follow the logic:

$$
\begin{aligned}
& \text { IF DATE }\left(\left[T_{n-1}\right]\right)=\operatorname{DATE}\left(\left[T_{n}\right]\right) \text {, } \\
& \mathbb{F}\left[\mathrm{LTL}_{n-1}\right]=\left[\mathrm{LTL}_{n}\right] \text {, THEN }\left[\mathrm{CC}_{n}\right]=\left[\mathrm{CC}_{\mathrm{n}-1}\right] \\
& \operatorname{ELSE}\left[C C_{n}\right]=0 \\
& \underset{=0}{\mathbb{F}}\left[\operatorname{LTL}_{n}\right]=1 \text {, THEN }\left[\mathrm{CC}_{n}\right]=\left[\mathrm{CC}_{n-1}\right]+1 \text {, ELSE }\left[\mathrm{CC}_{n}\right]=\left[\mathrm{CC}_{n-1}\right]
\end{aligned}
$$

\subsection{Data analysis}

With the legs sorted and organized, it is then possible to determine the average times for each activity: loading, loaded transport, unloading, unloaded transport and unproductive times.

In the application example, basically SUMIF and AVERAGEIF functions were used in Microsoft Excel to achieve the results. However, with the data organized one can get the same results regardless of the software or functions.

\section{Cycle time $\left[\mathrm{CT}_{\mathrm{i}}\right]$}

To sum up each cycle time, the spreadsheet program should follow the logic:

$$
\left[C T_{i}\right]=\sum_{\| \in\left[C C_{n}\right]=i}\left[L T_{n}\right]
$$

That is, $\left[\mathrm{CT}_{\mathrm{i}}\right]$ is the sum of the leg time $\left[\mathrm{LT}_{n}\right]$ if the cycle count $\left[\mathrm{CC}_{\mathrm{n}}\right]$ is equal to $\mathrm{i}$.

\section{Loading time $\left[\mathrm{CLT}_{i}\right]$}

To sum up each cycle loading time, the spreadsheet program should follow the logic:

$$
\left[C L T_{i}\right]=\sum_{\substack{\| \mathbb{E}\left(\left[C_{n}\right]=i \\ \mathbf{A N D}\left[L L_{n}\right]=1\right)}}\left[L T_{n}\right]
$$

That is, $\left[C L T_{i}\right]$ is the sum of the leg time $\left[\mathrm{LT}_{n}\right]$ if the cycle count $\left[\mathrm{CC}_{n}\right]$ is equal to iAND $\left[\mathrm{LL}_{n}\right]=1$.

\section{Unloading time [CUT $]$}

To sum up each cycle unloading time, the spreadsheet program should follow the logic:

$$
\left[C U T_{i}\right]=\sum_{\substack{\boldsymbol{U} \boldsymbol{A}\left(\left[C C_{n}\right]=i \\ \operatorname{AND}\left[C L_{n}\right]=1\right)}}\left[L T_{n}\right]
$$

That is, $\left[C U T_{i}\right]$ is the sum of the leg time $\left[\mathrm{LT}_{n}\right]$ if the cycle count $\left[\mathrm{CC}_{n}\right]$ is equal to $\mathrm{i}$ AND $\left[\mathrm{CL}_{n}\right]=1$.

\section{Loaded transport time $[$ CLTT $]$}

To sum up each cycle loaded transport time, the spreadsheet program should follow the logic:

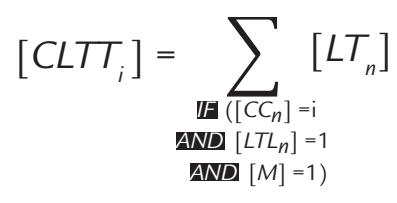

That is, $\left[C L T T_{i}\right]$ is the sum of the leg time $\left[\operatorname{LT}_{n}\right]$ if the cycle count $\left[C_{n}\right]$ is equal to i ANND $\left[L_{T L}\right]=1$ ANND $\left[M_{n}\right]=1$.

\section{Unloaded transport time [CUTT.]}

To sum up each cycle unloaded transport time, the spreadsheet program should follow the logic:

$$
\left[\mathrm{CUTT} T_{i}\right]=\sum_{\substack{\boldsymbol{u}\left(\left[\mathrm{CC}_{n}\right]=\mathrm{i} \\ \mathbf{A N D}\left[L T L_{n}\right]=0 \\ \mathbf{A N D}[M]=1\right)}}\left[L T_{n}\right]
$$

That is, $\left[\mathrm{CUTT}_{i}\right]$ is the sum of the leg time $\left[\mathrm{LT}_{n}\right]$ if the cycle count $\left[\mathrm{CC}_{n}\right]$ is equal to i AND $\left[\mathrm{LTL}_{n}\right]=0$ AND $\left[\mathrm{M}_{n}\right]=1$. 


\section{Unproductive time $\left[\mathrm{CUPT}_{\mathrm{i}}\right]$}

The time that the truck is not loading, unloading or transporting, is an unproductive time of the cycle, which can be defined as follow.

$$
\left[C U P T_{i}\right]=\left[C T_{i}\right]-\left(\left[C L T_{i}\right]+\left[C U T_{i}\right]+\left[C L T T_{i}\right]+\left[C U T T_{i}\right]\right)
$$

\section{Average times}

With all the information organized and classified, the average times of each op-

\section{Cycle classification}

To avoid using collected data that could disrupt the analysis, another string was created. This variable compares the cycle time with the average cycle times collected, recording the number 1 for cycles that should be

\section{Diesel consumption}

The consumption of diesel in liters per hour $(1 / \mathrm{h})$ was calculated by dividing

\section{Results}

In order to evaluate the proposed logic with the use of the materials described the system was tested in the application example. The data used in this study were collected during the period from January through February of 2018. One GPS sensor was installed in a truck, and the data were manually downloaded at the end of the day eration can be calculated using an AVERAGE function of the spreadsheet software.

considered and 0 for cycles that should not be considered.

Thus, the analysis will not consider extremely short cycles, which may have been due to some data collection error, or extremely long cycles, which

the liters of fuel that were supplied for the equipment by the number of hours worked.

and inserted into a Microsoft Excel worksheet pre-programmed with the proposed logic.

As the truck is always fueled with diesel at the end of the work shift, it always starts the day with a full tank. Thus, the volume of diesel supplied is the volume of fuel that was consumed for operation during that day. This con- may have been caused due to lunch stops or equipment breaks. The first and last cycle of the day are also discarded because they are the cycles in which the truck is going or coming from the parking place or diesel supply. sumption data was recorded manually. The Loading point [LP] was updated according to the mining advance and the Crusher Point $[\mathrm{CP}]$ was set. A Proximity radius $[R]$ of $30 \mathrm{~m}$ and a Speed tolerance $\left[\mathrm{V}_{\text {tol }}\right]$ of $5 \mathrm{~km} / \mathrm{h}$ were adopted.

Figure 1 shows the boxplot graph of the average times considering the data collected in the application example.

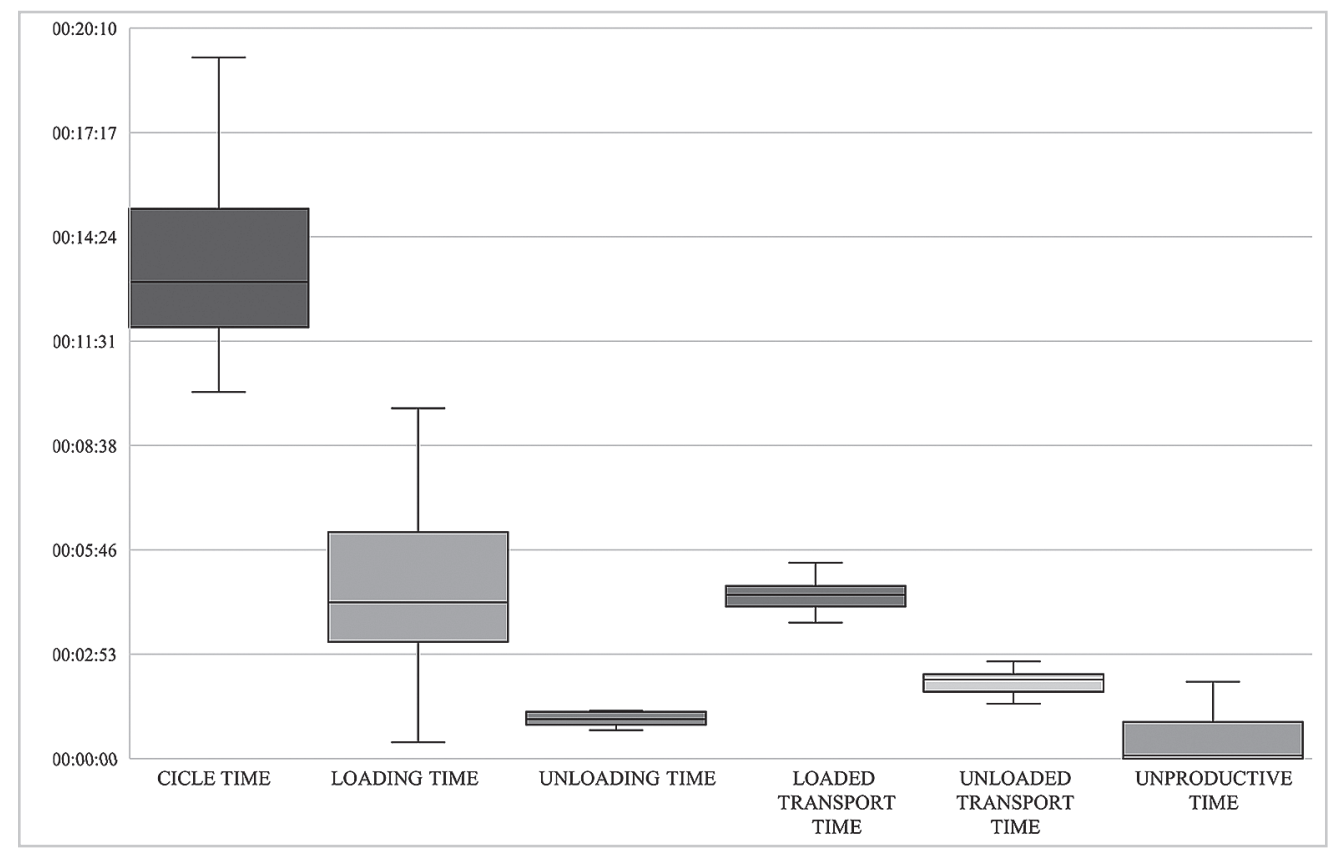

Figure 1 - Boxplot graph of the average times.

The data obtained were consistent. Cycle time, for example, has an average time of 14 minutes and 23 seconds with a standard deviation of 3 minutes and 55 seconds, and Unloaded Transport time presented an average of 2 minutes and 7 seconds with a standard deviation of 18 seconds. Only 15\% of the data were discarded due to the Cycle Classification.

In the application example the historical fuel consumption of the trucks was around $30 \mathrm{l} / \mathrm{h}$. During the period of application of the tool the average consumption of diesel presented an average of $27.8 \mathrm{l} / \mathrm{h}$, lower than the historical average.

The consistency of these results 
shows that it is possible to obtain data with the resources presented.
Table 4 shows the costs for perform-

ing the test in the application example.

Table 4 - Tests costs.

\begin{tabular}{c|c|c|c}
\hline Description & Qty & Unit cost (US\$) & Total cost (US\$) \\
\hline Garmin etrex 30X Portable GPS & 1 & 380.00 & 380.00 \\
\hline Office 365 - Annual subscription & 1 & 110.00 & 110.00 \\
\hline Total & & & $\mathbf{4 9 0 . 0 0}$ \\
\hline
\end{tabular}

\section{Discussion}

More important than the results obtained in the application example, this article aims to demonstrate that it is possible to monitor the production of the ore transport with a low-cost system.

Through a GPS sensor, spreadsheet software and simple logic programming it was possible to have a tool that measures the times of the main activities of the loading and hauling process. Considering the material used in the application example, this tool would cost approximately US\$
380 (Oct 2018 currency) for the GPS sensor and about US\$ 110 for annual subscription to the spreadsheet software, totaling US\$ 490. If GPS sensors were installed on all four quarry trucks, the solution would cost US\$1,630, as shown in Table 5.

Table 5 - Estimated cost for installation in all trucks of the Quarry.

\begin{tabular}{c|c|c|c}
\hline Description & Qty & Unit cost (US\$) & Total cost (US\$) \\
\hline Garmin etrex 30X Portable GPS & 4 & 380.00 & $1,520.00$ \\
\hline Office 365 - Annual subscription & 1 & 110.00 & 110.00 \\
\hline Total & & & $\mathbf{1 , 6 3 0 . 0 0}$ \\
\hline
\end{tabular}

Considering the application example, each truck cycle carries about $25 \mathrm{t}$ of ROM, $20 \mathrm{t}$ being salable material. If the average sale value is $10 \mathrm{US} \$ / \mathrm{t}$, each truck cycle generates a revenue of US\$ 200. Considering also a margin of $5 \%$ profit, each truck cycle would generate a profit of US\$ 10 .

Since the system cost was estimated at US\$ 1,630, 163 truck cycles would pay all the investment. In a quarry that produces 600,000 t per year of ROM, corresponding to 24,000 truck cycles, a slight increase in production of $1 \%$ would already be more than enough to make the system viable, including equipment, software and labor.

As shown, ore transport monitoring has not only brought economic benefits, but also brought environmental benefits. Considering the diesel consumption calculated during the appli- cation example, the number of annual cycles and the average cycle time, an annual saving of about 12,600 liters of diesel could be achieved in an operation the size of the application example.

According to EPA (2005), the burning of diesel generates 22.2 pounds of $\mathrm{CO}_{2}$ per gallon of diesel, or $2.7 \mathrm{~kg} \mathrm{CO}_{2} /$ liter of diesel. So, release of about 33 tons of $\mathrm{CO}_{2}$ per year would be prevented in this operation.

\section{Conclusions}

According to the data presented in this article, one can confirm that yes, it is possible to monitor the production of the ore hauling in a small mining operation with a low-cost system. Not only that, with the implementation of the tool, it is also possible to witness a reduction in fuel costs and consequently, better use of natural resources (minerals and fossil fuels).

A more elaborate sensor and pro- gramming could have been used. However, it is not the purpose of this article to explore to exhaustion the means to arrive at the final result, but rather to prove that with limited resources, it is possible to reach a relevant result.

The next steps of the research will be to determine technologies that could be used to obtain the results in order to eliminate the processing of the data in worksheets, and to automate the analysis and generation of indicators through cloud systems, focusing on small and medium companies and the low implementation and maintenance costs. Arduino and Raspberry are examples of technologies that could be tested on this type of system, due to low cost and simplicity. Once a technology has been defined, new functions could be added to the system, such as maintenance control and a dispatch system.

\section{References}

ARGHIRE, I. Microsoft's Office has over one billion users. Softpedia News, 10 July 2012. Available at: https://news. softpedia.com/news/Microsoft-s-Office-Has-Over-One-Billion-Users-280426.shtml. Accessed: april 2018.

AYYAGARI, M.; BECK, T.; DEMIRGUC-KUNT, A. Small and medium enterprises across the globe: a new database. Washington, D.C.: World Bank, 2003.

BACH, M. P.; ZOROJA, J.; VUKŠIĆ, V. B. Review of corporate digital divide research: a decadal analysis (2003- 
2012). International Journal of Information Systems and Project Management, v.1, n. 4, p. 41-55, 2013.

BARCLAY, C.; DUGGAN, E. W. Rethinking the digital divide: towards a path of digital effectiveness. In: HAWAII INTERNATIONAL CONFERENCE ON SYSTEM SCIENCES, 41th., 2008, Waikoloa, Hi. Proceedings. [S.l.]: IEEE, 2008. DOI: 10.1109/HICSS.2008.357.

BARTOS, P. J. Is mining a high-tech industry? Investigations into innovation and productivity advance. Resources Policy, Denver, n. 32, n. 4, p. 149-158, 2007.

BUGNOSEN, E. M. Small-scale mining legislation: a general review and an attempt to apply lessons learned. In: HILSON, G. M. The socio-economic impacts of artisanal and small-scale mining in developing countries. CRC Press, 2006. p. 5-21.

CARR, N. G. IT doesn't matter: HBR at large. Harvard Business Review, p. 41-49, 2003.

DEWAN, R.; RIGGINS, F. J. The digital divide: current and future research directions. Journal of the Association for Information Systems, v. 6, n. 12, p. 298-337, dec. 2005.

DNPM - DEPARTAMENTO NACIONAL DE PRODUÇÃO MINERAL. Anuário mineral brasileiro: 2010. Brasília, 2010. v. 35.

DUTTA, S.; MIA, I. (ed.) The global information technology report 2009-2010. Geneva: INSEAD, World Economic Forum, 2010.

EPA - US ENVIRONMENTAL PROTECTION AGENCY. Emission facts: average carbon dioxide emissions resulting from gasoline and diesel fuel. Washington: EPA, 2005.

GIOTOPOULOS, I. et al. What drives ICT adoption by SMEs? Evidence from a large-scale survey in Greece. Journal of Business Research, v. 81, p. 60-69, 2017. DOI: https://doi.org/10.1016/j.jbusres.2017.08.007.

HENTSHEL, T; HRUSHKA, F; PRIESTER, M. Global report on artisanal \& small-scale mining. London: IIED, WBCSD, January 2002. (Mining, Minerals and Sustainable Development, n.70).

HILLARY, R. Small and medium-sized enterprises and the environment: business imperatives. Abingdon: Routledge, 2017. $416 \mathrm{p}$.

KITTIPONGVISES, S.; CHAVALPARIT, O.; SUTTHIRAT, C. Greenhouse gases and energy intensity of granite rock mining operations in Thailand: a case of industrial rock-construction. Environmental and Climate Technologies, v. 18, n. 1, p.64-75, 2016, DOI: https://doi.org/10.1515/rtuect-2016-0014.

LEVESQUE, M.; MILLAR, D.; PARASZCZAC, J. Energy and mining - The home truths, Journal of Cleaner Production, v. 84, p. 233-255, 2014.

MAY, M. A. Application of queuing theory for open-pit truck/shovel haulage systems. 2012. $50 \mathrm{f}$. Thesis (Master of Science in Mining Engineering) - Virginia Polytechnic Institute and State University, 2012.

RIO TINTO: mine of the future: people and technology working together. [S. l.: s. n.], 2014. Available at: https://www. youtube.com/watch?v=91_EbGLItyY. Accessed: January 2018.

RODOVALHO, E. C.; LIMA, H. M.; DE TOMI, G. New approach for reduction of diesel consumption by comparing different mining haulage configurations. Journal of Environmental Management, v. 172, p. 177-185, 2016. DOI: http://dx.doi.org/10.1016/j.jenvman.2016.02.048.

SCHUTZ, L. et al. Value creation in exploration and development programs at Newmont's Nevada Gold Operations. In: SOCIETY OF ECONOMIC GEOLOGISTS CONFERENCE: wealth creation in the mineral industry, May 14-16, 2006, Keystone, CO, USA. Proceedings [...]. Keystone, CO: SEG, 2006. p. 83-86.

SEBRAE - Serviço Brasileiro de Apoio às Micro e Pequenas Empresas. Anuário do trabalho na micro e pequena empresa: 2012. 5. ed. São Paulo: DIEESE, 2012.

SILVA, A. B. A pequena empresa na busca da excelência. João Pessoa: Universitária, 1998.

TAYLOR, P. The importance of information and communication technologies (ICTs): an integration of the extant literature on ICT adoption in small and medium enterprises. International Journal of Economics, Commerce and Management, United Kingdom, v. 3, n. 5, p. 274-295, May 2015.

THE SME banking knowledge guide. Washington, D.C.: International Finance Corporation, World Bank Group, 2009.

VALE: caminhão fora de estrada sem motorista faz seus primeiros testes em Brucutu. Gonçalando, São Gonçalo do Rio Abaixo, MG, 26/01/2018. Notícias. Available at: http://www.saogoncalomg.com.br/pg.php?id_ cat=56\&\&id=3745. Accessed: 12 Feb 2018.

Received: 19 April 2019 - Accepted: 20 February 2020. 